\title{
EDITORIAL
}

\section{Mental health: why it still matters in the midst of a pandemic}

\author{
Antônio Geraldo da Silva, ${ }^{1}$ iD Débora Marques Miranda, ${ }^{2}$ iD Alexandre Paim Diaz, ${ }^{3}$ iD \\ Ana Luiza Silva Teles, ${ }^{4}$ Leandro Fernandes Malloy-Diniz, ${ }^{2-5}$ (iD Antônio Pacheco Palha ${ }^{1}$ (iD \\ ${ }^{1}$ Universidade do Porto, Porto, Portugal. Associação Brasileira de Psiquiatria (ABP), Rio de Janeiro, RJ, Brazil. Asociación Psiquiátrica de \\ América Latina (APAL), Brasília, DF, Brazil. ${ }^{2}$ Universidade Federal de Minas Gerais (UFMG), Belo Horizonte, MG, Brazil. ${ }^{3}$ Louis A. Faillace, \\ MD, Department of Psychiatry and Behavioral Sciences, The University of Texas Health Science Center at Houston, Houston, TX, USA. \\ ${ }^{4}$ Centro Universitário de Brasília (UniCEUB), Brasília, DF, Brazil. ${ }^{5}$ Universidade FUMEC, Belo Horizonte, MG, Brazil.
}

In times of fear and uncertainty, when threats to one's own survival and that of others become one of the main issues of daily life, many believe that mental health care can wait and that efforts should focus on preserving life. However, mental health is precisely one of the keys to surviving this latest pandemic and all that it entails in the short, medium, and long term, from the potential crisis in the provision of health services to helping preserve and reconstruct a postpandemic society. This editorial lists some topics in mental health that we believe are particularly worthy of attention at the moment and deserve full consideration both by health care workers and by the general population.

Driven by the angst and anxiety generated by a pandemic, thousands of people have flooded the health system, while others have rushed to supermarkets in an attempt to forestall coming supply shortages. Mathematical modeling will help us understand the natural history of the disease, predict outbreak patterns, and identify strategies to modify the course of the pandemic. Nevertheless, simple measures, such as behavioral interventions, are among the most critical mechanisms to reducing the impact of this pandemic - one of the greatest challenges this generation will face.

Effective quarantine, isolation, and preventive social distancing measures are essential components for managing a crisis such as the current pandemic. ${ }^{1}$ The first issue concerns mobility restrictions. In an article recently published in The Lancet, Brooks et al. ${ }^{2}$ calls for particular attention to the psychological effects of deprivation of liberty among those quarantined. Many have been slow to understand the importance of immediate isolation, or, even once this importance has been understood, will have resisted adoption of more restrictive measures, despite the fact that isolation has been one of the most efficient interventions to control spread of the infection in Asia. To illustrate the importance of these measures, we must go back the Middle Ages - more precisely, to the 14th century. The Black Death which plagued Europe, reaching its peak between the years 1347 and 1353, killed 30 to $50 \%$ of the general population. Several hypotheses have

Correspondence: Antonio Geraldo da Silva, SGAS 910, Ed. Mix Park Sul, BI. E, Salas 134/136, Asa Sul, Brasília, DF, Brazil.

E-mail: ag@abp.org.br

Submitted Mar 17 2020, accepted Mar 19 2020, Epub Apr 032020. sought to explain its cause and how quickly it spread. Recently, Gómez \& Verdú ${ }^{3}$ simulated linkages between population centers (cities, towns, villages) that were particularly affected at the time. The authors found that trade routes and religious pilgrimage routes were the most crucial vehicles for transmission, which reinforces the notion that people's movement can be one of the key factors in the spread of a pandemic. The main issue is that travel is among of the strongest of human habits, and respecting social isolation involves allocating mental resources to control this imperative. In the modern world, widespread global travel and heavy traffic in cities with many infected have been the key routes of dissemination. After any travel, individuals are forced to self-isolate, regardless of symptoms. This restriction of mobility and social contact, growing concern with dwindling financial resources, the need for constant attention and care so as not to infect others, and the terrible prospect of not knowing how long these measures will remain in place all cause anguish. Further sources of frustration include the postponement of personal projects such as travel and moving house, as well as the suspension of occupational activities, among others.

Given their importance, mobility-related interventions warrant objective, concerted efforts from government, the private sector, and individuals. Governments can and are creating conditions to minimize the financial and emotional impacts of isolation, e.g., by suspending tax payments and even proposing a universal basic income for the most vulnerable populations. The end goal of these measures is to make isolation feasible. The implementation of remote work, through well-defined measures such as replacing face-to-face activities with online solutions, reversing priorities (activities that do not require travel are implemented immediately, while those that do are postponed), and formally rescheduling (e.g., canceling and postponing) events, is an important step that must be taken by all corporate actors. Families should stick to a well-organized routine and create conditions to restrict circulation as much as possible, and always to the smallest number of family members. 
This takes us to a second, equally vital aspect: information, although essential, is often not sufficient to drive behavior change. Fortunately, this topic has been widely studied in cognitive psychology and behavioral economics. In addition to investing in information, other mechanisms can be used, including nudges. ${ }^{4}$ The concept of nudge theory has been popularized by behavioral economist Richard Thaler, the recipient of the 2017 Nobel Memorial Prize in Economic Sciences. Nudge theory essentially bets that small changes in the architecture of decision-making will change the frequency of given behaviors or decisions. Small changes in the environment and in the way alternatives are presented - nudges - can influence the way a person decides or behaves without requiring any coercive measures. An anecdotal case is that of the "Amsterdam urinals." In the men's restrooms of Schiphol International Airport, a plastic image of a housefly placed in the center of each urinal was found to be a more efficient measure than signage asking for patrons not to urinate outside the bowl. No man was ever instructed or required to "aim" at the fly. But the drive, however subtle, to "hit the target" increased the odds that men would aim their streams within the bowl, which led to massive savings in cleaning supplies and improved restroom hygiene. How could nudge theory be used to fight a pandemic? Some nudge-based alternatives have been proposed as containment measures in the United Kingdom. The Behavioral Insights Team, one of the most significant partners of the UK government in this endeavor, lists a number of nudgebased strategies in its website (https://www.bi.team/). One text describes simple strategies to modify habitual behaviors, such as touching one's face. One blog post on the Behavioral Insights Team website suggests a series of strategies that range from physical barriers (e.g., keeping one's hands busy or in one's pockets) through social strategies (e.g., asking friends of family members to call out "face" whenever one is about to touch one's face) to constant use of substitute objects (e.g., holding a plastic ball). Corporations can help by making hand sanitizer available at strategic locations in their facilities, which can be identified by reviewing service routines. We believe that nudges should not be used alone, but incorporated into other, already tried-and-true strategies. For example, scheduling online activities that require real-time participation can make working from home more effective than simply asking homebound employees to meet set goals at a given deadline. Keeping tabs on people through scheduled meetings that must be done online in real time combines nudge theory and social isolation strategies, and can be an important resource during this period.

A third important issue that warrants particular attention concerns the ways in which we make decisions and our cognitive biases. Immediacy is very difficult to control. Refraining from a pleasurable activity or from something we consider important in consideration of risk avoidance (even in the short term) or of future gain can be a major challenge. According to Keeney, ${ }^{5}$ personal decisions are related to the leading causes of death and are thus the target of many public-policy interventions. The author notes that decisions related to diet, high-risk (e.g., sexual) behavior, and habits (such as smoking and legal and illegal substance use) are associated with highly lethal conditions, such as coronary heart disease, metabolic disease, sexually transmitted diseases, and exposure to accident hazards. In our attempts to curtail the current pandemic, we will inevitably face issues related to individual decisionmaking. Refraining from pleasurable activities that bring immediate gain but involve risk, such as meeting friends or visiting close relatives, is crucial at this point. However, cognitive distortions are readily available to support these hedonistic, immediate decisions. "It won't happen to me." "I'm not part of the high-risk group." "We're not in the most dangerous phase of the curve yet." Shedding light on such beliefs and cognitive distortions is already an integral part of many public health initiatives, and can be leveraged in our approach to pandemics as well. For instance, Poland et al. ${ }^{6}$ highlighted the importance of addressing cognitive styles and beliefs in modifying responses to vaccination campaigns. The author highlights some cognitive decision-making styles, such as "denialist" (denies scientific evidence and bases stances on conspiracy theories), "innumerate" (cannot understand math and numbers, such as epidemiological data, when decision-making), "bandwagoning" (makes decisions in line with what others are saying), and "heuristic" (draws conclusions from isolated, insufficient information and makes overgeneralizations to protect one's own certainties). Belief modification involves initiatives to reach a large number of people (e.g., repeated dissemination of objective, simple information; identification of sources that feed inappropriate beliefs; pointing out inconsistencies and fallacies generated by heuristic thoughts) and, at the individual level, strategies such as those based on motivational interviewing. Addressing decision-making mechanisms and cognitive distortions should be an important target of current policies to control the COVID-19 pandemic. Repeating to oneself and to others that this is all "a hoax," "collective hysteria," or a "conspiracy" involving "just a Chinese flu" are good examples of distortions that must be explained and demystified. Mass education through reliable sources, as well as persuasion and outreach by health professionals, have an essential role to play in this process and must be adopted on a large scale, whether through individual contact, within corporations, or by government action.

A fourth crucial topic encompasses an important portion of the population, which is affected by various mental disorders. Considering only mood disorders and anxiety, more than $25 \%$ of the general population will be affected by a mental illness during their lifetime, ${ }^{7}$ and is thus more vulnerable to environmental stressors that affect decisionmaking. Deterioration of clinical symptoms of mental disorders can also have a negative impact on an already overburdened health care system. It is widely known that mental illness involves interactions between biological and social factors. These social factors are generally stressors, the intensity and content of which are perceived in a subjective manner. These stressors can be major triggers and drivers of depressive and anxious episodes, among other disorders. In a recently published study, Wang et al. ${ }^{8}$ assessed a sample of the Chinese population during the current pandemic and found an immediate psychological impact, with increased symptoms of anxiety, depression, and stress perception. Patients whose 
disorders feature impulsivity and immediacy as major characteristics, such as those with attention-deficit/ hyperactivity disorder, should receive particular guidance in terms of behavioral coping strategies and decisions with a long-term focus. The specter of adjustment disorder and posttraumatic stress disorders also looms for those who are experiencing (or are yet to experience) current stressors in a more acute and direct manner. Physicians and other health care workers will bear the brunt of the risk of infection and suffer the effects of exhaustion and burnout. There will be many such cases, since caring for patients is an immediate, urgent need that definitely cannot be postponed to a post-crisis period. Elective care should be rescheduled if possible, but maintaining current treatments, instructing patients on how to proceed until their next appointment, and organizing continuity of care are essential.

Finally, we must start preparing now for the coming months. Health care workers, particularly those who deal directly with mental health, will have to face the psychological effects of social distancing, isolation, quarantine, infection, and loss. Strategies to deal with these aspects include adopting clear, objective communication about what is happening, addressing prospects for the duration of restrictive measures, encouraging involvement in purposeful activities during this period, and highlighting the importance of isolation as an act of selflessness. Health providers involved directly in the care of patients affected by COVID-19 must have safe spaces at their disposal to receive mental health care, including psychopharmaceutical and behavioral resources. The harmful effects of discrimination and prejudice in relation to mental illness will only compound these issues. Structural stigma, which already deprives patients of adequate access to health services, can be heightened at this time of potential overload and collapse of health systems, and severe stress can contribute to both precipitating and worsening psychiatric conditions.

During the Black Death, physicians themselves exposed themselves to contamination while caring for thousands of patients and unknowingly helped spread the epidemic through contact with uninfected individuals. Bearing this in mind, measures and standards to ensure the safety of health care workers involved directly in the care of infected and symptomatic individuals have been widely implemented and disseminated. The shortage of personal protective equipment, medical devices, and other supplies must be addressed as an absolute priority. However, measures to safeguard the mental health of these professionals are equally important. There are already countless reports of panic and anxiety among health care workers faced with the perspective of massive care demands and the severity of the scenario. But little is known about the specific impact of this pandemic on the onset of mental illness among physicians, nurses, psychologists, and other providers on the frontline of caring for patients and their families. The first insights into this issue have come from recently published studies, such as that by Xiau et al. ${ }^{9}$ The authors found that Chinese physicians who cared for COVID-19 victims and had better indicators of social support were able to maintain better sleep quality, evidence of greater self-effectiveness, less intensity of anxious symptoms, and reduced impact of stressors. Creating purposeful activities can help mitigate impacts not only on health care workers but also on society as a whole. Several possibilities are available: setting up solidarity networks to deliver medicines and groceries to housebound older adults; compiling and publicizing lists of establishments that will still deliver their services and products while shut down; engaging in intense communication through media, online classes, and distance education activities; and disseminating high-quality content (museums with digital collections and virtual storytelling, for instance, can help keep children busy and involved). Health professionals should preserve their sleep schedules to the best of their ability, facilitate routines for their families, and be reassured that their close relatives will be cared for and safe, e.g., by keeping schools open for children of health care workers and law enforcement agents, as the UK has done.

Mental health care must be comprehensive and target the population as a whole when it comes to changing behaviors, beliefs, and attitudes. Special management and prevention interventions should focus on patients with psychiatric illnesses. Issues such as stigma and its segregationist consequences must be addressed. And the mental health of physicians and other frontline health care providers must be a priority. The mental health agenda remains urgent and essential, and should be one of the cornerstones of resilience in a society that will face a bewildering array of challenges as a result of this global pandemic.

\section{Disclosure}

The authors report no conflicts of interest.

\section{References}

1 Bedford J, Enria D, Giesecke J, Heymann DL, Ihekweazu C, Kobinger G, et al. COVID-19: towards controlling of a pandemic. Lancet. 2020;395:1015-8.

2 Brooks SK, Webster RK, Smith LE, Woodland L, Wessely S, Greenberg N, et al. The psychological impact of quarantine and how to reduce it: rapid review of the evidence. Lancet. 2020;395:912-20.

3 Gómez JM, Verdú M. Network theory may explain the vulnerability of medieval human settlements to the Black Death pandemic. Sci Rep. 2017;7:43467.

4 Thaler RH. Nudge, not sludge. Science. 2018;361:431.

5 Keeney RL. Personal decisions are the leading cause of death. Oper Res. 2008;56:1335-47.

6 Poland GA, Fleming DM, Treanor JJ, Maraskovsky E, Luke TC, Ball EMA, et al. New wisdom to defy an old enemy: summary from a scientific symposium at the 4th Influenza Vaccines for the World (IVW) 2012 Congress, 11 October, Valencia, Spain. Vaccine. 2013;31:A1-20.

7 Viana MC, Andrade LH. Lifetime prevalence, age and gender distribution and age-of-onset of psychiatric disorders in the São Paulo Metropolitan Area, Brazil: results from the São Paulo Megacity Mental Health Survey. Braz J Psychiatry. 2012;34:249-60.

8 Wang C, Pan R, Wan X, Tan Y, Xu L, Ho CS, et al. Immediate psychological responses and associated factors during the initial stage of the 2019 coronavirus disease (COVID-19) epidemic among the general population in china. Int $J$ Environ Res Public Health. 2020;17:1729.

9 Xiao $\mathrm{H}$, Zhang Y, Kong D, Li S, Yang N. The effects of social support on sleep quality of medical staff treating patients with coronavirus disease 2019 (COVID-19) in January and February 2020 in China. Med Sci Monit. 2020;26:e923549. 